\title{
Effectiveness Of Social Media On Youth In Relation To Their Social Life In Kerala
}

\author{
${ }^{1}$ Sheela K.D ${ }^{2 \cdot}$ Prof(Dr.)D.V.R Murthy \\ 1. Ph.D Research Scholar, (Regd No: MUR1501822) Mewar University Rajasthan \\ 2. Director Research, Deptt of Journalism \& Mass Comm, Andhra University
}

Article History: Received: 11 January 2021; Accepted: 27 February 2021; Published online: 5 April 2021

\begin{abstract}
Social Networking has become a global phenomenon. Millions of people now use internet to engage on social networks. As in, there are more than 300 Social Networking Sites (SNS) and the total number of people using Social Networking Sites around the world is 1.73 billion according to 2013 Sensex. In few years, the usage of Social Networking Sites has surprisingly grown. These Social Networking Sites offers a wide variety of resources and services such as messaging, sharing of information, online marketing, blogging, connecting, sharing photos, audios, videos, group discussion, and distribution of applications. Consequently; especially youth, are the avid users of these sites. And, the usage of Social Networking Sites among the youth has increased rapidly throughout the world. Evidently, Social Networking Sites have become significant part of our lives. However, the study has been set forward to analyse the influence of Social Networking Sites on the interpersonal relationships of youth in Kerala state. Humans are social animals and Interpersonal Relationships are a very vital aspect of human existence. Hence, the impact of Social Networking Sites on interpersonal relationships needs to be examined through the lens of Sociology.
\end{abstract}

\section{INTRODUCTION}

Media assumes a significant job in the lives of individuals all through the world, and Social Media have constantly assumed a urgent job in venturing up of globalization. It includes to our advancement procedure. Individuals around the bend gain through web based life, besides, numerous individuals have their work dependent on this. Really, it has turned into a piece of oneself. Individuals have made it so that it's hard to diminish down or to get free.

The Internet is considered as a leap forward in the globalization period. It has given a chance to assemble a worldwide correspondence base that would connection individuals around the globe together. The combination of the media has extended the use of web that brought forth online

networking. This specialized thought implies that the Internet can bolster and intervene new types of correspondence; consequently it helps in planning a superior social connection between people. Then again; Social media is an idea that has given individuals a typical stage for sharing their news, perspectives and feelings with respect to the happenings in and around the globe.

\section{SOCIAL NETWORKS}

It is a site that allows people with similar interests to come together and share information. Those who engage on social network sites as a personal endeavor interact by using the various bodies of media to discuss their lives and interests. E.g: Facebook, Instagram\&Snapchat.

- Facebook: Most browsed online social networking site with 150 Million users. It is clear that it will not fade away soon in India. For now, Facebook is one of the most well known long range interpersonal communication application destinations universally it licenses enrolled clients to make profiles like a 'divider' like include companions and communicate something specific, remark, transfer and offer recordings, photos, web joins.;- 'Gatherings' to broadcast occasions and welcome visitors and companions for going to that occasion;- 'Pages' to make and advance an individual or business thoughts or include others in a theme;- 'Nearness Technology' which permits video calls and content talk for those online on the site o 'Security' to square/permit specific or all individuals from review the profile, photographs or remarks.

- Instagram: In 2010, Instagram rapidly gained popularity, with one billion registered users in two months, 10 million in a year, and 800 million as of September 2017. In Apr 2012, Facebook acquired the military service for approximately US\$1 100000000000 in hard cash and stock. As of Oct 2015, over 40 billion photographs had been uploaded to the service. Although praised for its influence, Instagram has been the case of criticism, most notably for policy and interface changes, allegations of censorship, and illegal or improper content uploaded by users. The $1 / 4^{\text {th }}$ population of India uses Instagram where posting Selfies has 
become the trends. According to Times of India, there are 90\% Instagram users in India, who are below 30 years.

- Snapchat: Snapchat has millions of active users in India. Picking up Traction Among Older Millennials. $2 \%$ of those 35 and older used Snapchat, compared with 5\% of those 25 to 34 years old and $24 \%$ of those 18 to 24 years old. Snapchat represents a new, mobile-first direction for social media, and significant emphasize on the user interaction with stickers and Increased reality objects.

\section{PROBLEM FORMULATION}

Person to person communication Sites are significant devices of correspondence, stimulation and partaking in this period. In that capacity there has been significant ascent in its utilization particularly in the Indian Society. Indeed, the adolescents are increasingly inclined to be engaged with Social Networking locales than some other gathering. Long range interpersonal communication Sites encourage sharing of data, expanding contacts, etc. However an extraordinary change has been seen relating to the utilization of Social Networking Sites in connection to relational connections among this age gathering.

However, there has been constant speculation about the changes in the interpersonal relationships due to the SNS. The interpersonal relationships are said to face drastic changes especially among the youth, being the most frequent and ardent users. Consequently a study is required to analyse this aspect in a detailed manner. It is noteworthy that very little research work has been conducted in this aspect especially in the Indian context. For a more specialized study youth in India are focused upon. Youth have a high probability to be affected by Social Networking Sites. They spend most of their time on these sites thus it is essential to study this category for the better understanding of the nature of their interpersonal relationships and the variables affecting them.

Therefore, the present study is conducted to examine the influence of the usage of Social Networking Sites on the changing nature of interpersonal relationships of youth. Particularly, the researcher seeks answers to the following questions:

a) What is the profile of the students in terms of using Social Networking Sites? (towards their: Frequency of Using, Purpose of Using, Number of friends, etc.).

b) What is the influence of Social Networking Sites on interpersonal relationships of youth (towards their: Family, Friends, Teachers and Others).

\section{OBJECTIVES}

The objective of this research paper is listed below.

1. To examine the socio-economic status of the sample population,

2. To examine the uses of social media by the sample population in their day today activities

3. To examine the utilization process by the sample population for their career and social life.

4. To ascertain the effectiveness of social media on the sample population in the process of their personal relationships.

5. To explore the effectiveness of mediated communication in personal communication among the peer groups in the sample population,

6. To explore the effectiveness of mediated communication in family communication in the sample population,

7. To compare the effectiveness of mediated communication with other modes of communication such as telephone, letters, personal contacts and so on.

8. To integrate, harmonize and link three secondary resume data sets with media content and upshot data.

9. To develop and equivalence four methods for empirically examining media effects using mark -sectional and venire sight data. in alignment with the strategic priority of agreement behavior in multi-floor contexts, to test hypotheses regarding links between media system of rules, news media content and political cognition .

10. To conduct experiments on media effects to provide a benchmark for the above four methods and adjudicate issue when inconsistent

11. To determine the usage of specific social networking sites by the youth.

12. To analyze the credibility over the information received from social networking sites.

13. To understand the pros and cons of social networking sites known by the youth.

14. To study the influence of social networking sites on the personal and professional life of the youth. 


\section{LITERATURE REVIEW}

Gilbert M. Talaue(2018) assess the impact of social media on academic performance of selected college students. In this article, the authors raise the actual impact of daily communication of youth in social media. Descriptive research design was utilized to gain accurate profile of situation. Business Administration and Management Information System students who are actively using social media are the respondents of the study. It was conducted during the summer semester of academic year 2017- 2018.Summing-up,social networks becomes an integral part of the students' full life, took up most of their free time.Undoubtedly, in social networks, there are also things useful for the development of the students. In addition, communication with peers through social networks can help a student socialize, find new friends, discuss with them issues related to studies. Thus, it can be concluded that social media have a dual impact on student achievement, and it is necessary to approach adolescents' use of social networks with ultimate responsibility.

Sadaf Mustafa(2018) study is to highlight the pros and cons of using social media by the students and emphasize on the positive usages. Mixed results are found while analyses were made on the basis of literature reviewed. It is observed that the use of social media and specifically social networking websites does not always have negative impacts. There are also some positive insights those are detailed in the paper under study. If correctly analyzed and appropriate strategies are formulated and implemented for the use of social media; it will certainly bring improvements in the knowledge and study patterns of university students. It is observed that social networks are also being used by the research students. Therefore, this paper will also help support in the field of research.

Rajeev M.M. and Jobilal(2015) Society is influenced by social media in myriad ways. It is the media that help them to get information to form opinions and make judgments regarding various issues. It is the media which keeps the people updated and informed about what is happening around them and the world. Here the researcher studied the various impacts of mobile phone among the youth in social relationships. The very specific objectives of the study are (1) to study the influence of other social networking sites or contributing factors on the usage of mobile phones among the respondents (2) to study the extent use of that mobile phones are used the respondents (3) to analyze the positive and negative impacts of mobile phones among the respondents. The study uses the simple random sampling method. The samples were collected from the boys and girls of selected classes. The sample size of the study is 50 respondents. The finding and recommendations of the study highlights the vast scope of social media in the development aspects, meanwhile, the negative impact of mobile phones and other associated supplies are very high. The sensitization and intervention programmes are the real need of the hour to control the ill effects of social net working sites among the teenagers.

Khurana N (2015) The study of this research aims to create an immense level of awareness among the youth exposed to such social networking sites and findings will not only bear results as to how adversely and positively is the youth affected by the usage of these sites but also will help the youth to understand the usage of these networking sites efficiently. Facebook, My Space, Twitter, LinkedIn, Skype and Ning are a few such sites that attract maximum of the youth to tune in to them and thereby embodies their own merits and demerits that desperately need to create an actual picture among the youth. It has now become an evident and usual sight to face individuals being insensitive to chat in worshipping places, homes when relatives and guests are around, highways, schools, colleges and social gatherings wherein they are so preoccupied and engrossed into their phones that they do not even bother to look up as to where they are which results in their inability to prioritize as to what is important and what isn't. Attention has thus been shifted from real to virtual world and visible to invisible friends.

IoannaBizirgianni (2013), made a study of a constantly evolving field such as Information and Communication and Social Media, in specific as that of youth tourism. The phenomenon of Social Networking has excited many researchers at the international level because of the rapid development of new technologies and has made efforts to study their relation to the traits of young people personality, and especially those related to their travel behavior. It is now clear that the everyday life of young people is affected by internet and Social Media as a field of interest for policymakers and researchers leads the tourism industry to realize the needs of young people through this change and respond to this challenge.

Keol Lim and Ellen B Mier (2012) in the study highlighted how Korean students use social networking sites. The study shows how the number of International Students Getting admissions in US universities has increased due to increasing usage of Social Media. Not surprisingly, the apprehensions of parents and educators about SNS are also comparable to past questions about how youth spend their time. SNS represent a new environment through which to examine adolescent development and learning.

Craig A. Anderson (2012) studied; many children and youth spend an inordinate amount of time consuming violent media. Although it is clear that reducing exposure to media violence will reduce aggression and violence, it is less clear what sorts of interventions will produce a reduction in exposure. The sparse research literature suggests that 
counter attitudinal and parental-mediation interventions are likely to yield beneficial effects, but that media literacy interventions by themselves are unsuccessful.

Meier and Keol (2012), conducted a research in United States on how international students use Social Networking Sites and how does the use of SNS impact on their academic adaptation. Further finding of the study showed that the students or respondents were benefitted from their use of Social Networking Sites and it helped to decrease the anxiety by providing them with new means of connecting their family and friends.

Kuan-Yu Lin and His-Peng Lu (2011) applied network externalities and motivation theory to understand the usage of Social Networking Sites among college students. After conducting an empirical research involving 402 samples, using Structural Equation Modelling (SEM) Approach, Lin and Lu (2011) found that "Enjoyment" was the most influential factor for the increasing usage of Social Networking Sites among the college students.

Jayme, Waddington (2011); It concluded that Social networking among youth is not just a fad; it is part of their culture. While social networking can expose youth to danger, they are exposed to the same dangers in real life as well. We have officially been labeled as the "Dumbest generation" by author Mark Bauerlein, due to our heavy use of technology. However, current tools make one's social network an explicit and visible resource from which to get that information. SNS, through the use of profiles and friend networks, enhance the ways in which people share information about themselves, their friends, and their lives. Again, the focus of Web 2.0 applications has been to connect persons rather than information. Self-disclosure also plays a large role in SNS effects on well-being. Specifically, researchers posit that when youth disclose and express more information about themselves the quality of their relationships improves.

Moira Burke and Cameron Marlow (2011) in a study entitled "Social Capital as Facebook differentiating uses and users" discussed about the perspective look at the uses of Social Networking Sites. The study stated the usage of SNS is treated as Monolithic activity. In this study a survey was conducted using 415 Facebook users, the study revealed that receiving messages from friends is associated with increasing the bridging social capital. The main goal study was to research hoe different uses of SNS impact different users.

Bicen and Cavus (2010) evaluated the usage of Social Networking Sites among students in the department of computer education instructional technology and found which social networking sites are the most preferred by students. The study revealed that use and sharing of knowledge on Internet is made an integral part of college students' lives. Results show that Live Spaces and Facebook are the commonly used sites by the students.

\section{RESEARCH METHODOLOGY}

Research is a process in which the researcher wishes to find out the end result for a given problem and thus the solution helps in future course of action. Research has been defined as "A careful investigation or enquiry especially through search for new fact in any branch of knowledge". Research methodological analysis is the specific procedures or techniques used to identify, select, process, and analyze information about a topic. In a research newspaper publisher, the methodology division allows the reader to critically evaluate a field of study 's overall validness and reliability. The methodology section answers two main head : How was the data collected or generated? How was it analyzed? It is a process used to collect data and information for the purpose of making business decisions. The methodology may include publication inquiry, audience, sketch and other research techniques, and could include both present and historical information. This research incorporates a quantitative approach to study the research object. Sampling has been done effectively and the cock that has been employed to piece of work on the data collecting is particularly questionnaire where the doubt was end ended along with usage of tools such as pie chart. A survey was conducted in order to object the age bracket (15 to 24). The sampling has been taken mainly from the Delhi /NCR area. In all, questionnaires were filled and reciprocated enthusiastically by the respondents.

They were asked a total of 10 questions. On being asked as to which mixer networking site the target audience uses the most, Facebook has respondents of about $75 \%$ holding the maximum plowshare amongst the quietus. Instagram has respondents of about $15 \%, 6 \%$ responded to Chirrup and only $4 \%$ responded to Linkedin thereby proving that maximum of the audience's share is inclined towards the platform of social utility that connects them with their Quaker and peers who live around them other than a pro platform that passes them an opportunity to professional networking.Globe -wide, large phone number of someone are present on sociable networking situation and marketers have Begin to realize that these website can good turn out to be an important puppet for selling. Out of 2 .51000000000000 active net users globally, 1.8 million are the members of one or more social networking land site (Business Macrocosm, 2014). The inquiry as well as inquiry supervisor were of the view in the year 2009-10 itself that the presence of people on social networking sites is going to be bigger and better and it would be a great theme to discovery out whether these sites can be used as successful marketing platform and also assess what kind of roadblocks might be faced in the process. After detailed deliberations the precise problem that was chosen is 
"Opportunities and challenges in marketing through social networking sites." This research endeavor would help in fathoming out the opportunities and challenges confronting the marketers through social networking sites and help in making specific recommendations to design effective marketing strategies. The procedure using, which researchers go about their work of describing, explaining and predicting phenomena, is called Methodology. Methods are the ways of obtaining information useful for assessing explanation. Research methodology is a way to systematically solve the research problem. It is a plan of action for a research project and explains in detail how data are collected, analyzed and presented, so that they will provide meaningful information. Research methodology is making a systematic study to achieve the truth. It includes the identification of study area, the procedure for collecting data, analyzing the data, and finding the conclusion or truth based upon the scientific procedure. Research in common parlance refers to search for knowledge. In fact, research is careful, systematic investigation or inquiry for search of new facts in any branch of knowledge.In today's world, there is a muckle of plug surrounding social media unsurprisingly, considering the medium itself created the very concept of going viral. According to the Gartner plug bend for new applied science, a flow of hype and inflated anticipation is followed by the "manger of disillusionment" during which we become more critical of a new concept or technology we've bargain into and believed in its inherent value. Questions ensue. Does it really do what it promised? How I can trust this data? Am I getting Return on invested capital out of this? It's during this latter phase where the new technology has to mature and prove that it is worthy to become a stall, ongoing component part of our world. This is where I believe social media is today, and now is the time for social to prove its credentials as an inquiry methodological analysis.

\section{DATA ANALYSIS}

In understanding to the table and the bar diagram underneath demonstrates that, it is seen that youths having age bunch between 24 to 26 years are most extreme in test populace. Out of the absolute respondents of 290 , 50 respondents (17.24\%) were separately between 18 to 20 years old, 80 respondents $(27.59 \%)$ were individually between 21 to 23 years old, and 90 respondents (31.03\%) were individually between 24 to 26 years old, 70 respondents $(24.14 \%)$ were 27 to 29 years old respectively.

Table 1.1 Age of respondents

\begin{tabular}{|l|c|c|}
\hline Particular & \# of Respondents & Respondents Percent \\
\hline $18-20$ & 50 & $17.24 \%$ \\
\hline $21-23$ & 80 & $27.59 \%$ \\
\hline $24-26$ & 90 & $31.03 \%$ \\
\hline $27-29$ & 70 & $24.14 \%$ \\
\hline Grand Total & $\mathbf{2 9 0}$ & $\mathbf{1 0 0 . 0 0 \%}$ \\
\hline
\end{tabular}

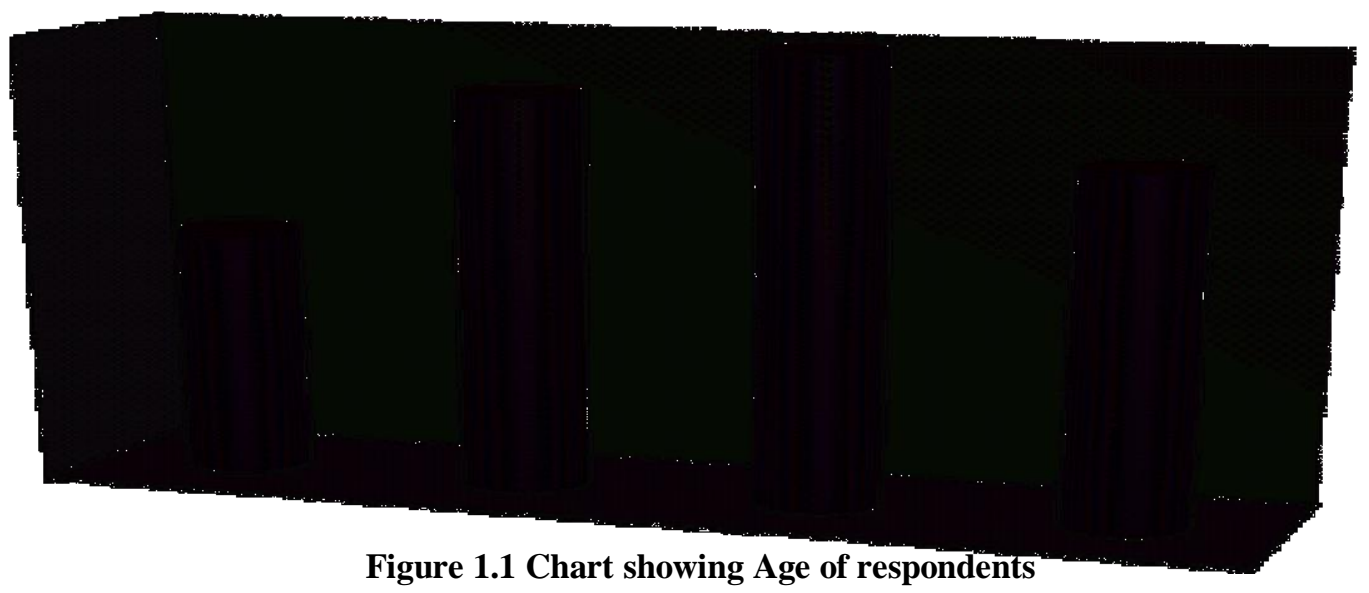


The study done by the sample universe is shown below. According to the Kerala state, we observe to have women majorly high in number. But in this study we have taken both the genders cumulatively. On the other hand, the table and the pie chart below show that, male and female respondents are equal. Out of the total respondents of 290, 145 respondents $(50.00 \%)$ were male and where as the remaining half i.e. 145 respondents (50.00\%) were female.

Table 1.2 Gender of respondents

\begin{tabular}{|l|c|c|}
\hline Particular & \# of Respondents & Respondent Percent \\
\hline Male & 145 & $50.00 \%$ \\
\hline Female & 145 & $50.00 \%$ \\
\hline Grand Total & $\mathbf{2 9 0}$ & $\mathbf{1 0 0 . 0 0 \%}$ \\
& & \\
\hline
\end{tabular}

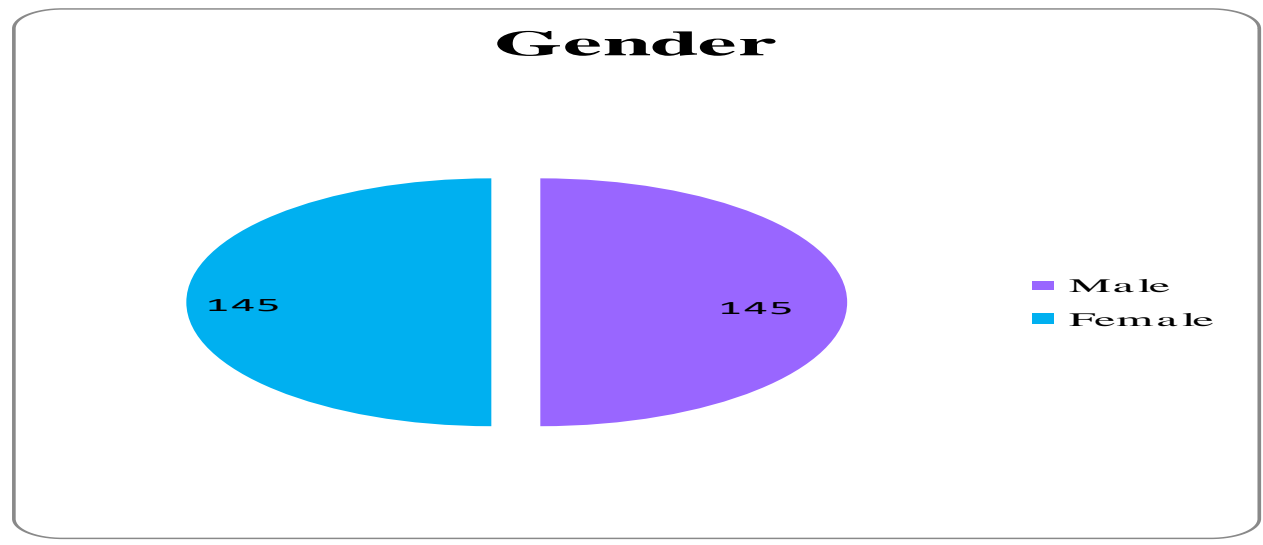

Figure 1.2 Chart showing gender of respondents

As you see, as the instruction capability expands, the less percent of respondents have appeared. It is watched fundamentally that as the training capability expands the percent of respondents are bit by bit decreased down. In any case, surprisingly the proportion could have been equivalent however this expresses how steadily individuals are advancing, the significance of carrying on with a life is more than the internet based life. This unmistakably demonstrates how under graduates are increasingly engaged in the long range informal communication, likewise as a result of the less duty towards living and having it progressively over the way of life.

Out of the total respondents of 290, 90respondents (31.04\%) were graduates, 50respondents $(17.24 \%)$ were post graduates and 150 respondents $(51.72 \%)$ were under graduates.

Table 1.3 Table showing qualification of respondents

\begin{tabular}{|l|c|c|}
\hline Particular & \# of Respondent & Respondent Percent \\
\hline Post Graduate & 50 & $17.24 \%$ \\
\hline Graduate & 90 & $31.04 \%$ \\
\hline Under Graduate & 150 & $51.72 \%$ \\
\hline Grand Total & $\mathbf{2 9 0}$ & $\mathbf{1 0 0 . 0 0 \%}$ \\
\hline
\end{tabular}




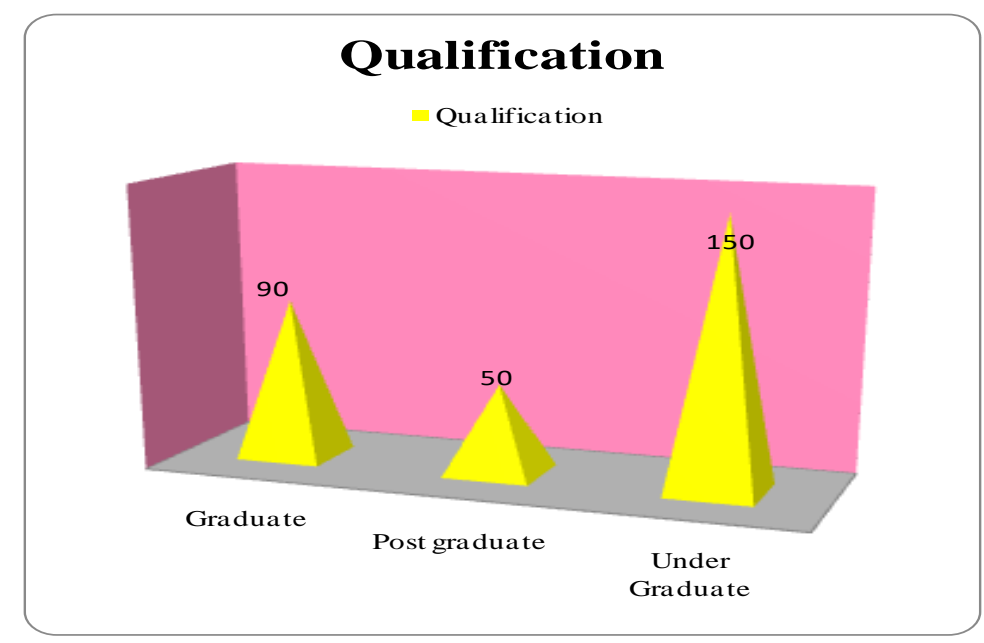

Figure 1.3 Chart showing qualification of respondents

Social media is a vital part of people's life, especially the younger generation- the youth! However, it's likely that social networking have taken over a lot of peace, time \& a lot more. Yet it depends on person to person, but youth have $100.00 \%$ access and command over the networking. An average person will spend 5 years of his/her life on social media - more than they will spend on eating, socializing and grooming, as people continue to spend more time on social media, that number will only increase gradually. The table and the bar chart below shows that, the respondents use social networking sites. Out of which the total respondents are 290, all the 290 respondents $(100.00 \%)$ answered yes.

Table 1.4 Table showing respondents using social networking sites

\begin{tabular}{|l|c|c|}
\hline Particular & \# of Respondent & Respondent Percent \\
\hline No & 0 & $0.00 \%$ \\
\hline Yes & 290 & $100.00 \%$ \\
\hline Grand Total & $\mathbf{2 9 0}$ & $\mathbf{1 0 0 . 0 0 \%}$ \\
\hline
\end{tabular}

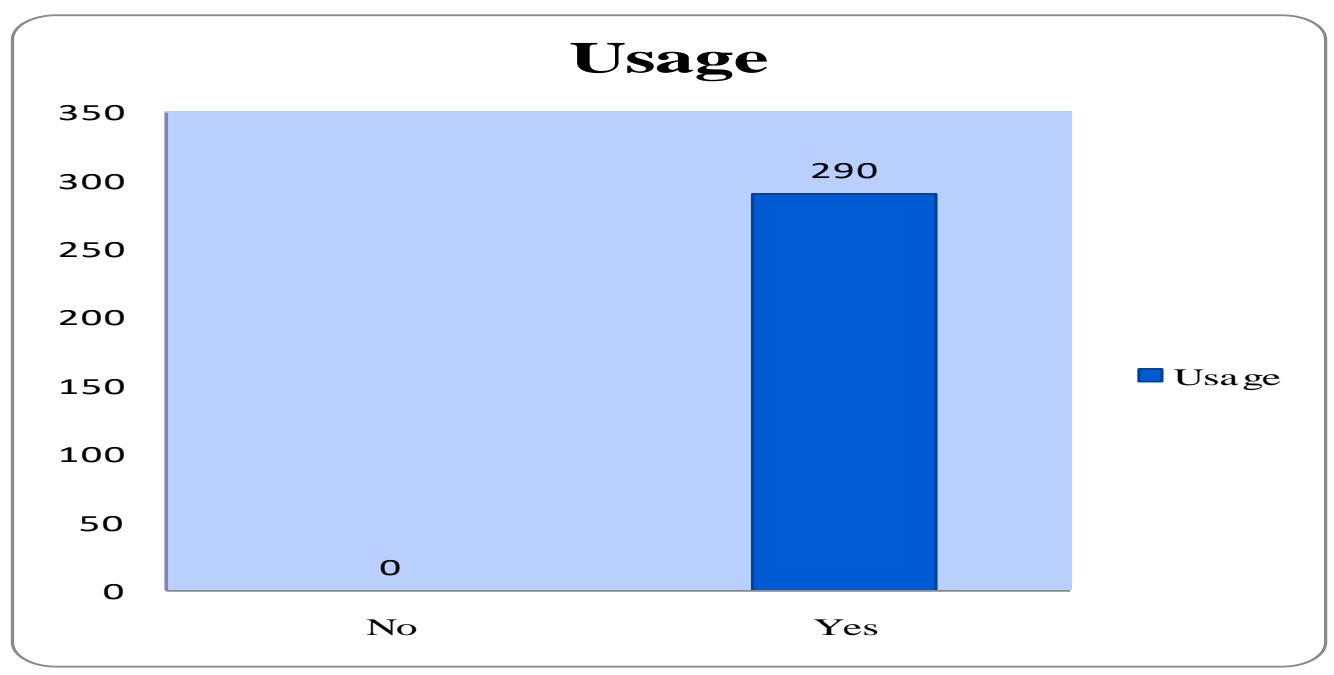

Figure 1.4 Chart showing respondents using social networking sites 
Mobile phones are the ideal method to remain associated with others and furnish the client with a feeling that all is well with the world. In case of crisis, having a wireless can enable assistance to contact you rapidly and could spare lives. In any case, the significance of mobile phones goes path past close to home security. Given below is the table and pie chart to specify the context above. Most of the youngsters are using mobile phones to access social networking sites. Out of the total respondents of 290, 280 respondents (96.55\%) answered yes, and 10 respondents $(3.45 \%)$ answered no.

Table 1.5 Table showing use of social networking sites on mobile phones

\begin{tabular}{|l|c|c|}
\hline Particular & \# of Respondent & Respondent Percent \\
\hline No & 10 & $3.45 \%$ \\
\hline Yes & 280 & $96.55 \%$ \\
\hline Grand Total & & $\mathbf{1 0 0 . 0 0 \%}$ \\
& $\mathbf{2 9 0}$ & \\
\hline
\end{tabular}

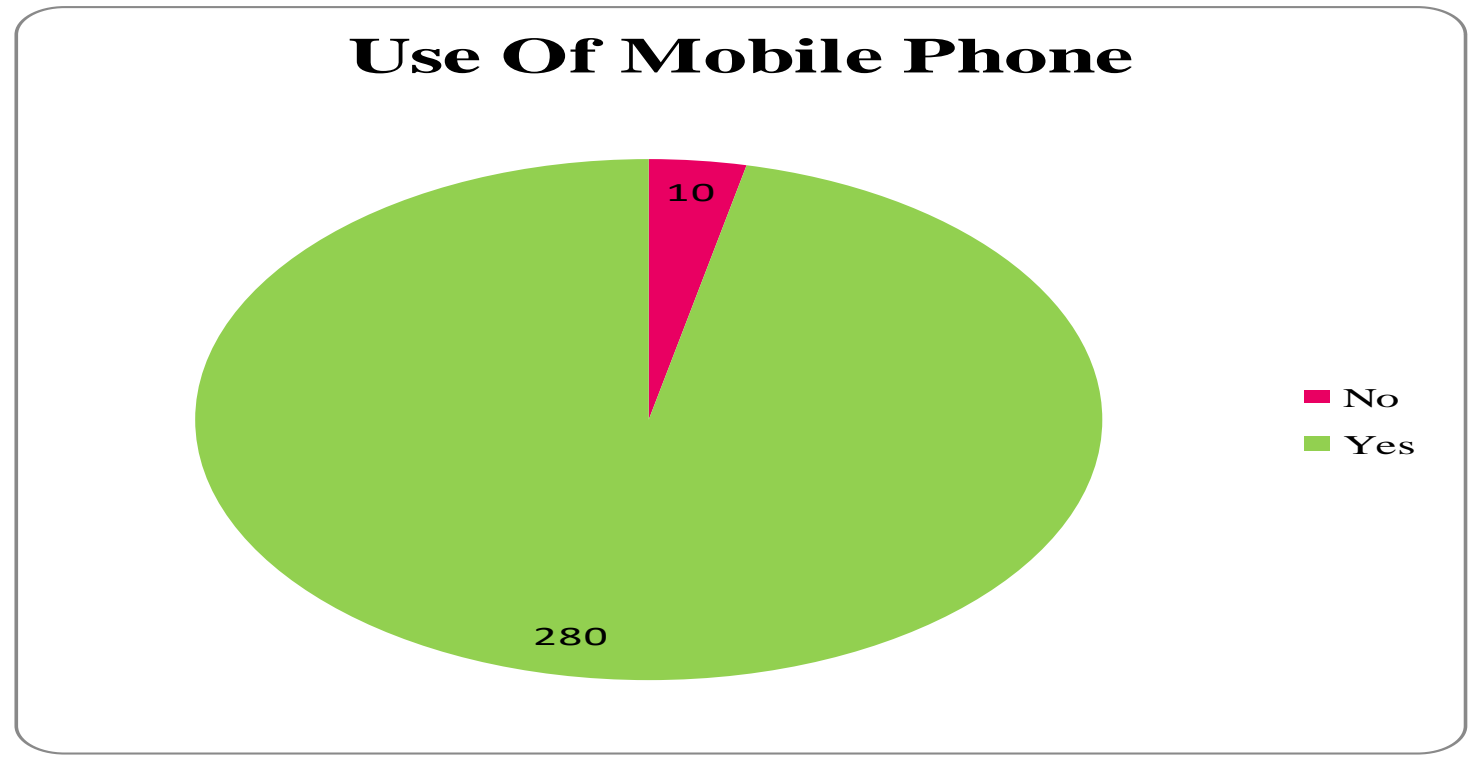

Figure1.5 Chart showing use of social networking sites on mobile phones

We have taken the most popular favorite form of social media sites used by the youth. Face book is forward from $90 \%$, followed by YouTube from 70\%, then followed by Skype 60\%, followed by twitter 50\%, and others $20 \%$. The table and the bar chart below shows that, all the students used one or the other social networking site. The social networking sites that students used for academic purposes included YouTube, Google plus and Face Book. Twitter was the least used of all the websites. Out of the total respondents of 290, 90 respondents (31.03\%) uses Face Book, 70 respondents (24.14\%) uses YouTube, 60 respondents (20.69\%) uses Skype, 50 respondents (17.24\%) uses Twitter and 20 respondents $(6.90 \%)$ uses Other form of social media.

Table 1.6 Table showing favorite form of social media of respondents

\begin{tabular}{|l|c|c|}
\hline Particular & \# of Respondents & Respondents Percent \\
\hline FaceBook & 90 & $31.03 \%$ \\
\hline
\end{tabular}




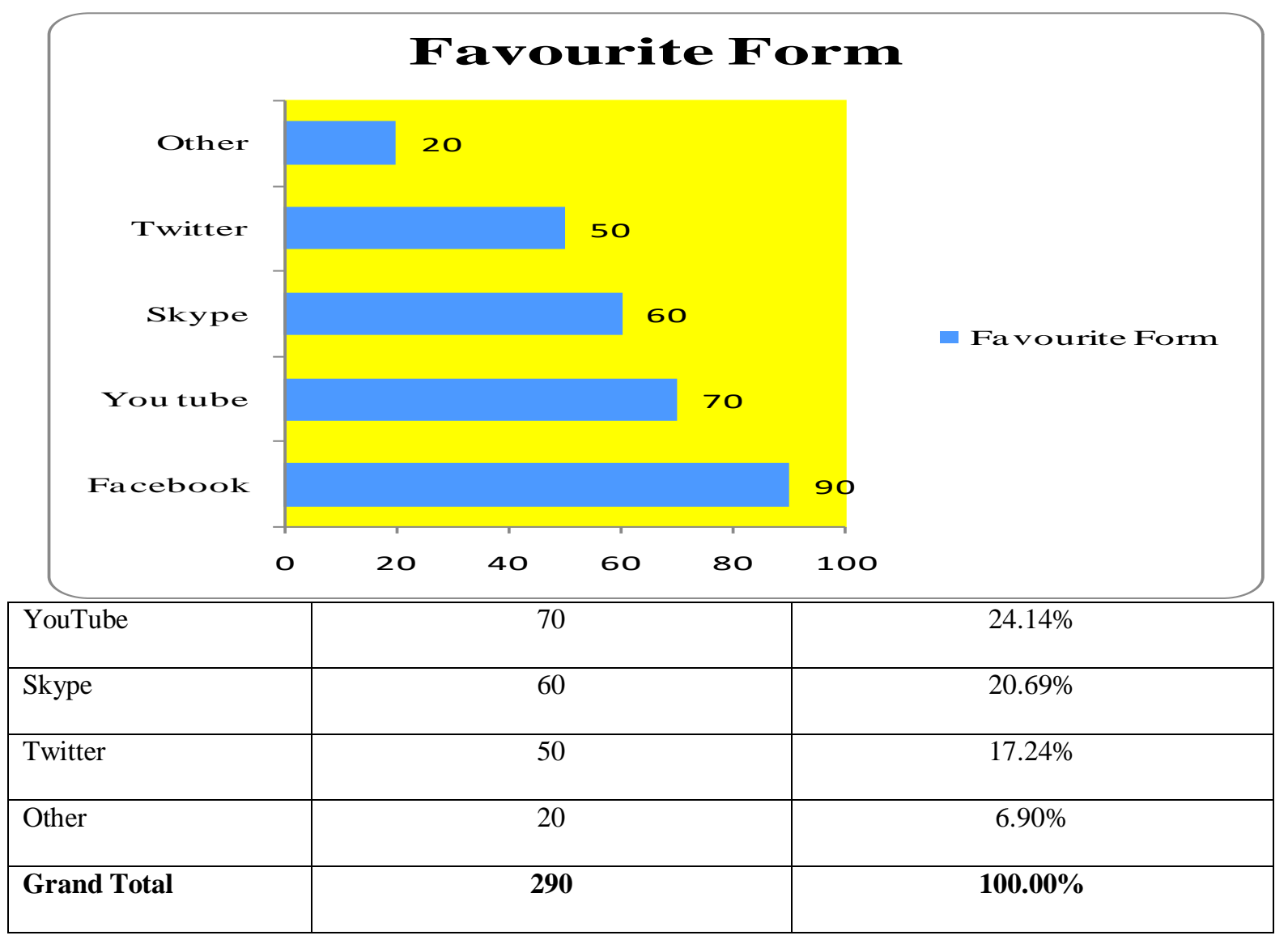

Figure 1.6 Chart showing favorite form of social media of respondents

Youth who are more focused towards life, career and have the basic understanding of how to use the platforms, they are likely to use it less or so. Youth who can't think of running their day or life without social media they are more likely to use is more than a year.The table and the line chart below shows that, students are having their accounts since more than a year. As a result, youngsters using social networking site. Out of the total respondents of 290, 10 respondents (3.45\%) uses social media from less than a month, 50 respondents $(17.24 \%)$ uses social media from $2-3$ months, 60 respondents $(20.69 \%)$ uses social media from 6 months or 1 year, 170 respondents $(58.62 \%)$ uses social media from more than 1 year.

Table 1.7 Table showing Respondents using social networking sites

\begin{tabular}{|l|c|c|}
\hline Particular & \# of Respondents & Respondents Percent \\
\hline Less than a month & 10 & $3.45 \%$ \\
\hline $2-3$ months & 50 & $17.24 \%$ \\
\hline 6 months or 1 year & 60 & $20.69 \%$ \\
\hline More than 1 year & 170 & $58.62 \%$ \\
\hline Grand Total & $\mathbf{2 9 0}$ & $\mathbf{1 0 0 . 0 0 \%}$ \\
\hline
\end{tabular}

Figure 1.7 Chart showing Respondents using social networking sites 


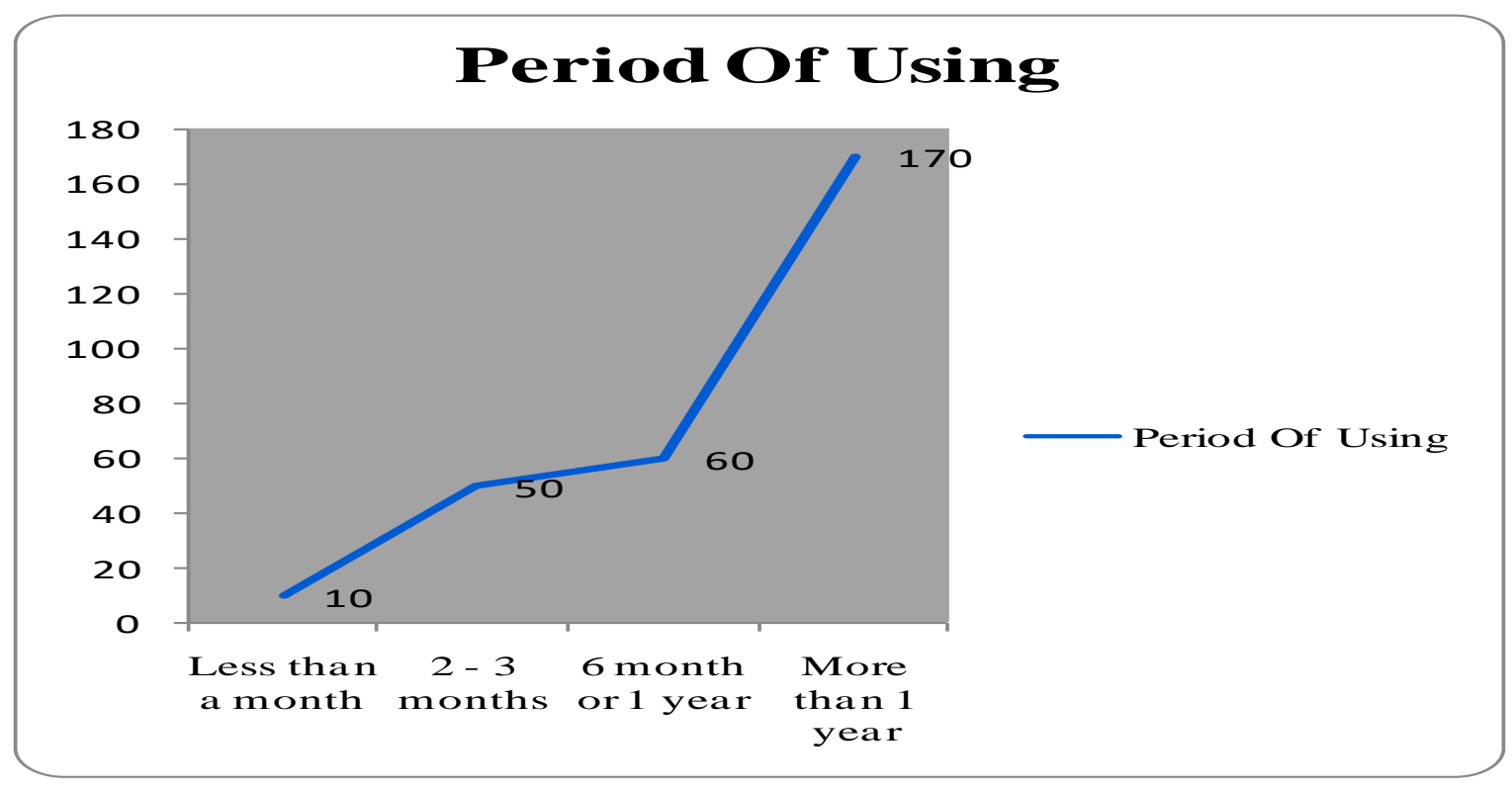

\section{CONCLUSION}

The analysis of primary data clearly states that the intervention of SNS has caused for significant changes in interpersonal relationships between college students and their family. Hence there is a major influence of SNS on the college student's changing interpersonal relationships with members of their family.

Further, these changes in interpersonal relationships are positive changes. These positive impacts on interpersonal relationships help college students to build cordial and intimate relationships with members of their families.

The usage of Social Networking Sites influences interpersonal relationships between college students and their friends and teachers. Here too, in order to understand the influence of Social Networking Sites on the interpersonal relationship of college students with their friends and teachers the researcher has used five point scales.

The purpose of this research work was to examine the Social Networking sites usage patterns of youth and the impact of Social Networking sites on their lives and behavior. It is found that Social Networking sites are very popular among the youths with the majority of them stating that they are active members of social networks.

The current study has shed light on the evolving nature of Social Networking sites among youngsters illustrating the reasons why they use Social Networking sites, what information they shared and the impact of Social Networking sites on them.

The finding of this study can be used for further research work on Social Networking sites and its impact on interpersonal relationship amongst youngster, culture and education.

It was found that these social networking sites are acting as great medium for view mobilization. People are feeling free in sharing their thoughts on any issue and even youth is raising their voice against social acts like violation of Human Rights, corruption etc. These social networking sites are proving themselves a boon at least in bringing thoughts of people on these social issues.

It is also being generated from the information so obtained that people are getting more aware about the social issues mainly from Face book. But instead of getting this knowledge the people generally don't discuss them and if they do, they just sign off the sites after discussion and the issue just remains focused on web only.

It was found that women's are spending less time on these sites mainly for 10-30 minutes yet they are more sensitive towards these social issues. Most of the people think that youth can play a positive role in changing our society which is represent in most of the responses to different queries.

\section{REFERENCES}

1. Aaltonen, S. Kakderi, C. Hausmann, V. and Heinze, A. 2013. "Social Media in Europe: Lessons from an Online Survey". 18th UKAIS Annual Conference: Social Information Systems. Worcester College. Oxford, UK. 
2. Ahmad, Ateeq. 2011. "A Short Description of Social Networking Websites and Its Uses". International Journal of Advanced Computer Science and Applications, Vol. 2, No.2 pp. 124-128

3. Akyildiz, Muge and Argan, Metin. 2011. "Using Online Social Networking: Students' Purposes of Face book Usage at the University of Turkey". Journal of Technology Research. 1, 1-11.

4. Alexa (2015). The top 500 sites on the web. Retrieved from http://www.alexa.com/topsites

5. Alexander, B. 2006. "Web 2.0: A New Wave of Innovation for Teaching and Learning?". Educause Review, 41, 32-44.

6. Alexander, Jeffrey C. (ed.). 1988. "Durkheimian Sociology: Cultural Studies". Cambridge: Cambridge University Press.

7. Althaf, Marsoof. 2011. "Online Social Networking and the Right to Privacy: The Conflicting Rights of Privacy and Expression". Int. Jnl. of Law and Info. Technology, Pp. 110-132.

8. Alvin, Malesky L. and Chris, Peters. 2011. "Defining Appropriate Professional Behavior for Faculty and University Students on Social Networking Websites". Springer Science and Business Media.

9. Annabi, H., McGann, S. T. (2013). Social media as the missing link: Connecting communities of practice to business strategy. Journal of Organizational Computing and Electronic Commerce, 23, 56-83. doi:10.1080/10919392.2013.748608

10. Anne, West. Jane, Lewis and Peter, Curries. 2009. "Student Face book 'Friends': Public and Private Spheres".

11. Antony, Wing Kosner. 2013. "Next is the Social Network for the near Future". The Sunday Times.

12. Appropriateness of Content". Cyber psychology and Behavior, 11 (1), 95-97.

13. Archibald, M. M., Radil, A. I., Zhang, X., Hanson, W. E. (2015). Current mixed methods practices in qualitative research: A content analysis of leading journals. International Journal of Qualitative Methods, 14, 5-33. $\quad$ Retrieved from http://ejournals.library.ualberta.ca/index.php/IJQM/article/view/23006

14. Arnold, N., Paulus, T. (2010). Using a social networking site for experiential learning: Appropriating, lurking, modeling and community building. The Internet and Higher Education, 13, 188-196. doi:10.1016/j.iheduc.2010.04.002

15. Ayelet, Noff. 2011. "The Future of Social Media". The Next Web Blog.

16. SHUKLA, NEHA. "SOCIAL MEDIA \& ITS INFLUENCE ON CUSTOMER RELATIONSHIP IN INDIAN RETAIL SCENARIO." International Journal of Sales \& Marketing Management Research and Development (IJSMMRD) 7.4 (2017): 27-34.

17. Jayaram, B., et al. "A Survey On Social Media Data Analytics And Cloud Computing Tools." International Journal of Mechanical and Production Engineering Research and Development, 8 (3), 243254 (2018).

18. AL ASSAF, KHALED TAWFEQ. "IMPACT OF ADVERTISING MESSAGES ACROSS SOCIAL NETWORKS ON CONSUMERS'PURCHASING BEHAVIOR OF MOBILE PHONES: A STUDY AMONGST YOUTH IN JORDAN." International Journal of Sales \& Marketing Management Research and Development (IJSMMRD) 7 (2017): 9-14.

19. BARUA, BIKASH, and SAYAKA ZAMAN. "ROLE OF SOCIAL MEDIA ON BRAND AWARENESS IN PRIVATE UNIVERSITIES OF BANGLADESH." International Journal of Business Management \& Research (IJBMR) 9.6, Dec 2019, 1-12

20. Katz, Yaron. "Social Media Is Powerful, but Can It Change Policies of Institutionalized Organizations Such as the Israeli Army?." International Journal of Humanities and Social Sciences (IJHSS) 6.6 (2017): 29-34.

21. Khan, M. S., et al. "Effect of social media on enhancement of English learning proficiency at university level in Khyber Pakhtunkhwa." Journal of Humanities and Social Sciences 2.2 (2016): 71-84. 